\title{
Stable Carbon-Centered Radicals Based on N-Heterocyclic Carbenes
}

\author{
Rajendra S. Ghadwal* (D) \\ Anorganische Molekülchemie und Katalyse, Anorganische Chemie \\ und Strukturchemie, Centrum für Molekulare Materialien, Fakultät \\ für Chemie, Universität Bielefeld, Universitätsstraße 25, 33615 \\ Bielefeld, Germany \\ rghadwal@uni-bielefeld.de
}

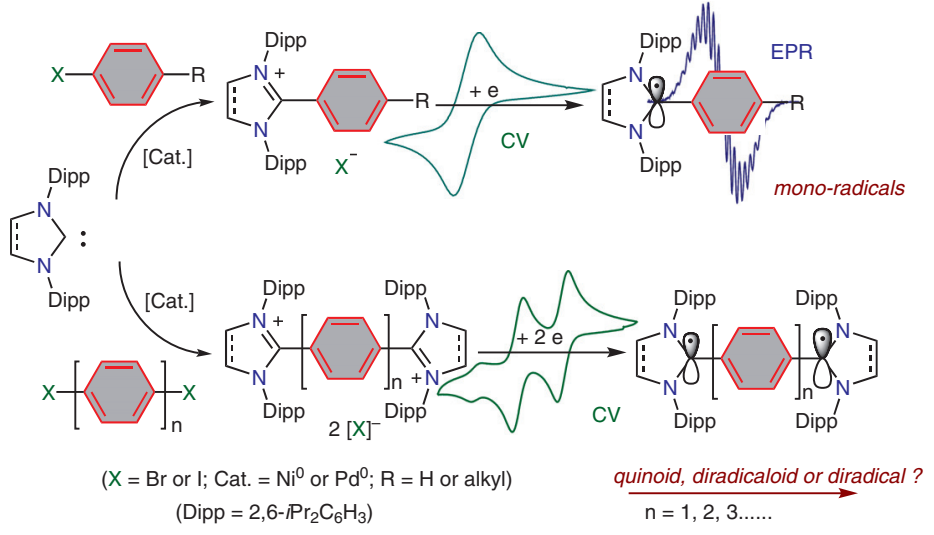

$\left(\right.$ Dipp $\left.=2,6-\mathrm{Pr}_{2} \mathrm{C}_{6} \mathrm{H}_{3}\right)$
Accepted after revision: 23.06.2019

Published online: 12.07 .2019

DOI: 10.1055/s-0037-1611887; Art ID: st-2019-a0289-a

Abstract Carbon-centered radicals and diradicaloids based on classical $\mathrm{N}$-heterocyclic carbene (NHC) scaffolds are readily accessible as crystalline solids. The presence of an aryl ( $\mathrm{Ar}$ ) substituent at the C2-position is the key to the remarkable stability of these open-shell species as it provides appropriate room for the spin-density delocalization. Two catalytic as well as high-yielding protocols have been developed to install a suitable aryl group at the C2-position of NHCs. The spin-density in mono-radicals $\left(\mathrm{NHC}^{\mathrm{Ar}}\right)^{\cdot}$ is mostly located on the parent carbene carbon (C2) atom. The bridging of two NHCs through a phenylene spacer $\left(\mathrm{C}_{6} \mathrm{H}_{4}\right)_{n}$ enables the isolation of various $p$-quinodimethane ( $p$-QDM) derivatives, which may be considered as open-shell Kekulé diradicaloids. The diradical character of these NHC-analogues of Thiele $(n=1)$, Chichibabin $(n=2)$, and Müller $(n=3)$ hydrocarbons [ $(\mathrm{NHC})\left(\mathrm{C}_{6} \mathrm{H}_{4}\right)_{n}(\mathrm{NHC})$ ] can be tuned by a rational choice of the size and/or the topology of spacers. In this account, the synthesis, structure, and properties of this new class of radical hydrocarbons is presented.

1 Introduction

NHC-Monoradicals

NHC-Diradicaloids

Conclusion

Key words radical, diradical, diradicaloid, carbene, hydrocarbon, heterocycle, open-shell, paramagnetic

\section{Introduction}

Radicals are fundamental intermediates ${ }^{1}$ and they play crucial roles in numerous biological ${ }^{2}$ and industrially important processes. ${ }^{3}$ In general, radicals are short-lived species and, therefore, in a condensed phase, spontaneously react with surrounding (solvent, precursor, or by-product) molecules, undergo self-decomposition or dimerization to eventually form closed-shell products. ${ }^{4}$ Consequently, syn- thetic access to thermally stable ${ }^{5}$ radicals for detailed structural investigations has been a subject of intense fundamental interest for augmenting our understanding about chemical bonding and electronic structure. ${ }^{6}$ In addition, stable radicals are also highly promising class of compounds for their potential applications in materials science and emerging areas. ${ }^{7}$ This is because of their unique optical, electronic, and magnetic properties. ${ }^{6 b, 8}$ The potential of stable radicals as unique building blocks for the design of nextgeneration advanced functional materials for applications in optoelectronics, spintronics, and solar cells is substantial. ${ }^{9}$ The incorporation of stable radicals into artificial molecular machines (AMMs) is very appealing because an electron's spin can be much easier and more precisely controlled, even with a smaller energy input, than a charge. ${ }^{7 \mathrm{c}}$ In this context, carbon-centered radicals have special advantages because of their planar trivalent nature, which promises structural diversity and elaborate designs. Stable radicals are also of immense interest as active materials in organic radical batteries (ORBs). ${ }^{10}$ These so-called 'eco batteries' have the potential to be cheaper, safer, and longer-lasting than current metal-based batteries and, thus, are of ever-growing importance in our modern technologybased society. ${ }^{11}$ This becomes evidently more appealing if such radicals are derived from 1,3-imidazoli(ni)um precursors, which are promising electrolytes for battery applications. In recent years, radical catalysis has also emerged as an important tool in organic synthesis. ${ }^{12}$

\section{Stable Radicals and Radicaloids}

In 1900, Gomberg isolated the first stable radical, the triphenylmethyl I (Scheme 1 ). ${ }^{13}$ This seminal report marked the dawn of stable radical chemistry. I, however, undergoes self-association in the condensed phase, yielding the $\sigma$-dimer II. Although the delocalization of the unpaired electron 
over the phenyl rings contributes to the stability of I, steric shielding of the central carbon atom that retains the most spin density is considered the key factor. The use of bulky substituents at para- or meta-position(s) of the phenyl groups slows down the dimerization to some extent, but no monomeric species could be isolated. Derivatives containing ortho-substituted or perchlorinated aryl groups were found to be remarkably stable. Because of the synthetic modularity, triphenylmethyl derivatives remain the most well-known class of stable carbon-centered radical hydrocarbons reported to date. Nonetheless, only heavily substituted or chlorinated species are isolable as monomers. ${ }^{14}$ The presence of two unpaired electrons in a molecule adds additional complexity to the electronic structure. Molecules containing two unpaired electrons in two nearly degenerate molecular orbitals are called diradicals, which may have parallel (triplet) or antiparallel (singlet) spins. ${ }^{8}$ Depending on the interaction between the unpaired electrons, singlet diradicals are further classified as open-shell (OS) and close-shell (CS) singlets. It should however be noted that the nature of the singlet wave function changes progressively from an OS to a CS configuration. Thus, the region in which the triplet becomes strongly destabilized and where the OS singlet becomes a CS singlet is not clearly defined. The term 'diradicaloids' is used for molecules with partial singlet diradical nature in their ground state. ${ }^{15}$

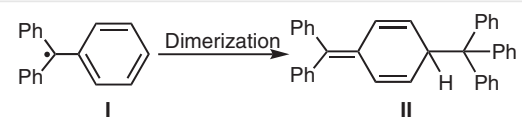

Scheme 1 The triphenylmethyl (trityl) radical I and its $\sigma$-dimer II
After the isolation of the trityl radical I, Thiele reported the phenylene bridged compound III ( $n=1$; Scheme 2$)$ in 1904. ${ }^{16}$ In 1907, Tschitschibabin isolated a related derivative III $(n=2)$ featuring a biphenylene bridge. ${ }^{17}$ In general, they can be described either as an OS diradical (IIIa) or a CS quinoid (IIIb) structure. This is, however, not very straightforward. The electronic structure and properties of these socalled Thiele's (TH) and Chichibabin's ( $\mathbf{C H})$ hydrocarbons had been a subject of intense scientific discussion for more than 70 years, and this issue came to be known as 'the Biradical Paradox'. ${ }^{18}$ In 1986, Montgomery et al. ${ }^{19}$ determined the solid-state molecular structures of these highly reactive species by single-crystal X-ray diffraction. Currently, $\mathbf{C H}$ is generally described as a diradicaloid (a resonance hybrid of IIIa and IIIb) with a significant diradical character, whereas TH is considered as a $p$-quinodimethane ( $p$-QDM). This can be explained based on the recovery of one (TH) and two (CH) Clar's aromatic sextet ring(s) in the OS diradical forms IIIa. ${ }^{20}$ Obviously, the Müller's hydrocarbon $(\mathbf{M H})^{21}$ with a terphenylene (I, $n=3$ ) bridge reported in 1941 has higher diradical character compared with $\mathbf{T H}$ and $\mathbf{C H}$. So, the $\mathbf{M H}$ is extremely reactive and it remains a challenging task to obtain pure samples for reliable measurements.

Stable diradicaloids delocalized over $\pi$-conjugated systems are appealing synthetic targets because of their unique physical properties and potential applications in nonlinear optics, molecular electronics, and organic spintronics. ${ }^{22}$ In this context, $\mathbf{T H}, \mathbf{C H}, \mathbf{M H}$, and related molecules serve as very promising model systems. Over the past few years, different synthetic strategies have been developed to thermodynamically and/or kinetically stabilize various an-

\section{Biographical Sketches}

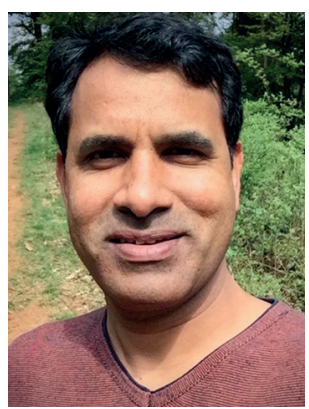

Rajendra S. Ghadwal studied chemistry at the University of Rajasthan Jaipur. In 2008, he joined the research group of Professor Herbert W. Roesky at the Georg-August-Universität (GAU) Göttingen as a postdoctoral research fellow. His postdoctoral work was focused on stable silylenes and silicon-heteroatom multiple bonded compounds. He started his independent research career at the GAU Göttingen in 2011 with a special emphasis on the development of unconventional carbon-donor ligands for organometallic catalysis and for the stabilization of open-shell main-group compounds. He re- located his research group in 2015 from Göttingen to Bielefeld in Germany. In 2016, he completed his Habilitation in inorganic chemistry under the mentorship of Professor Dietmar Stalke at the GAU Göttingen and subsequently rehabilitated (Umhabilitation) at the Bielefeld University. He is currently a Privatdozent at the Bielefeld University and leading the 'Molecular Inorganic Chemistry and Catalysis' research group (www.ghadwalgroup.de). His research endeavors on the exploration of open-shell maingroup compounds, $\pi$-conjugated molecular frameworks, basemetal ( $\mathrm{Ni}$ and $\mathrm{Cu}$ in particular) catalysis with mesoionic carbenes (MICs), optoelectronic properties of MIC-metal complexes, small molecules activation and functionalization aim to advance fundamental low-valent main-group element (including carbon) chemistry for sustainable synthesis and advanced functional materials. He recently received a Feodor Lynen Research Fellowship for Experienced Researchers from the Alexander von Humboldt Foundation to collaborate with Professor Christopher C. Cummins at the Massachusetts Institute of Technology (USA). 


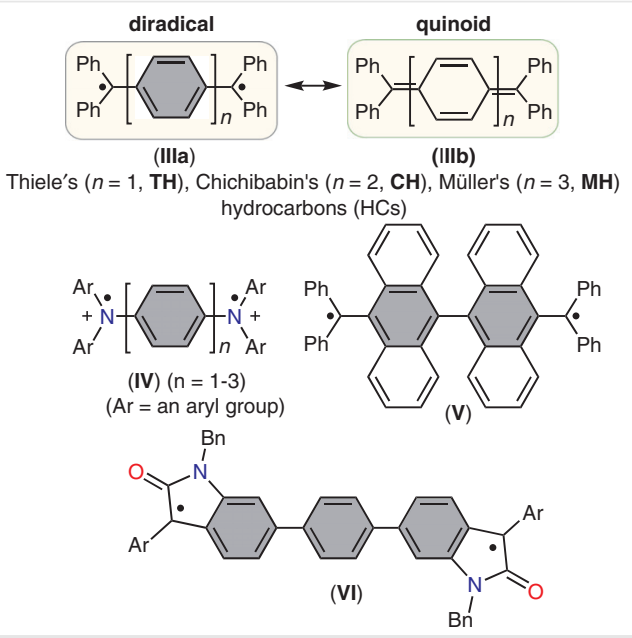

Scheme 2 Diradical (IIla) and quinoid (IIIb) resonance forms of Thiele's $(n=1)$, Chichibabin's $(n=2)$, and Müller's HCs and selected examples of analogous dicationic bis(triarylamino) (IV) and benzannulated ( $\mathbf{V}$ and VI) derivatives

alogues of $\mathbf{T H}, \mathbf{C H}$, and $\mathbf{M H}$. Bis(triarylamine) dications IV (Scheme 2) are isoelectronic to III, in which the $\mathrm{Ph}_{2} \mathrm{C}^{\cdot}$ moiety of III is replaced by an $\mathrm{Ar}_{2} \mathrm{~N}^{+\cdot}$ unit. ${ }^{23}$ The benzannulation approach has also been successfully employed to isolate stable polycyclic hydrocarbons such as $\mathbf{V}^{9 a, 24}$ In 2017 , Wu et al. reported the oxindolyl-based carbon-centered diradicaloid VI, an analogue of the MH. ${ }^{25}$ Synthetic strategies to various carbon-centered stable radicals have been summarized in some recent review articles. ${ }^{6 b, 26}$

$\mathrm{N}$-Heterocyclic carbenes (NHCs VII; Scheme 3) are very versatile $\sigma$-donor neutral ligands and have been extensively explored in transition-metal chemistry and catalysis. ${ }^{27} \mathrm{Sim}-$ ilarly, numerous compounds containing a low-valent maingroup element, ${ }^{28}$ including radicals (VIII) ${ }^{29}$ have been stabilized by the use of NHCs. In this context, the success of Bertrand's cyclic alkyl amino carbenes (CAACs, IX) in stabilizing open-shell main-group or transition-metal species is remarkable. ${ }^{30}$ This is because of the favorable electronic structure of CAACs. The smaller HOMO-LUMO energy gap of CAACs compared with classical NHCs makes them not only stronger $\sigma$-donors but also very efficient $\pi$-acceptors with respect to the latter. ${ }^{31}$ The enhanced electrophilicity of CAACs originates from the low-lying $\pi^{*}\left(\mathrm{C}_{\text {carbene }}-\mathrm{N}\right)$ orbital that allows captodative ${ }^{32}$ interactions between the carbene (IX) and a main-group moiety (E) in the corresponding derivatives $(\mathbf{X}) .^{30 \mathrm{a}-\mathrm{d}, 33}$ Various carbon-centered stable radicals have been also isolated using CAAC-frameworks. ${ }^{34}$ In contrast, stable organic radicals derived from NHCs (VII) have so far remained limited to some specific compounds featuring a redox active nitrogen or sulfur atom(s). ${ }^{35}$

Our research foci of developing new catalytic structures for sustainable synthesis ${ }^{36}$ and accessing open-shell maingroup compounds $\mathrm{s}^{27 \mathrm{~b}, 37}$ for advanced functional materials relies on the development as well as exploration of uncon-

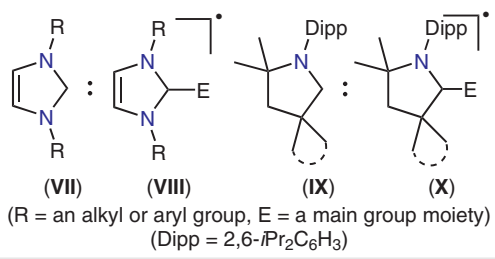

Scheme 3 NHC (VII) and NHC-stabilized main-group radicals (VIII). CAAC (IX) and CAAC-stabilized main-group radicals ( $\mathbf{X})$

ventional carbon-donor ligands/scaffolds. For this purpose, we use classical NHCs as fundamental structural motifs to design new ligand sets. ${ }^{38}$ This is because of the easy synthetic accessibility and tunable steric as well as electronic properties of NHCs. The available structural variables (Figure 1) in NHCs offer a plethora of opportunities to fine-tune the properties of derived molecules in many ways. These variables clearly appear to be more important and decisive in addressing the stability issue of highly sought-after open-shell molecules. Therefore, NHCs are an ideal choice for the design of stable radicals with adaptable properties. 1,3-Imidazolium salts $\mathbf{X I}\left(\mathbf{R}^{\prime}=\mathrm{H}\right)$ are typical precursors to NHCs (VII) (Scheme 4). Their cyclic voltammograms (CVs) exhibit a very negative reduction potential (ca. $-2.3 \mathrm{~V}$ vs. $\mathrm{Fc} / \mathrm{Fc}^{+}$) that is irreversible. ${ }^{39}$ Not surprisingly, chemical reduction of $\mathbf{X I}\left(\mathrm{R}^{\prime}=\mathrm{H}\right)$ with potassium in refluxing THF affords free NHCs (VII). The formation of VII is believed to result from the decomposition of unstable radical XII-H. ${ }^{39}$ Muon resonance spectroscopy ( $\mu \mathrm{RS}$ ) studies showed that VII reacts with $\mathrm{Mu}^{*}$ (muonium, a hydrogen atom equivalent) to generate the radical $\mathbf{X I I}-\mathrm{Mu}$, analogous to $\mathbf{X I I}-\mathrm{H}^{4}{ }^{40}$ The XII-Mu species was calculated to feature the nonplanar radical center with $74.9 \%$ of the spin density located at the carbene-carbon atom.

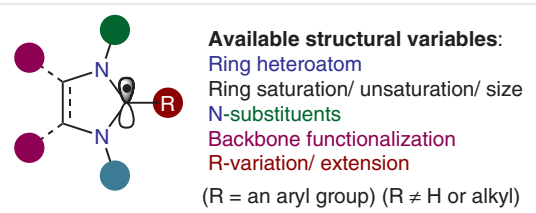

Figure 1 Available structural variables in classical NHC-based radicals

These early studies clearly emphasize the requirement of a suitable substituent at the C2-position of XI to stabilize putative NHC-radicals. We previously showed that various transition-metal ${ }^{36}$ as well as main-group element ${ }^{38,41}$ compounds featuring a mesoionic carbene (MIC), which may also be referred to as abnormal NHCs (aNHCs), ${ }^{42}$ XII can be readily prepared by the deprotonation of $\mathrm{C} 2$-arylated $1,3-$ imidazolium salts XII $\left(R^{\prime}=A r\right)$ and in no case was cleavage of the $\mathrm{C} 2-\mathrm{C}_{\mathrm{Aryl}}$ bond observed (Scheme 4 ). This encouraged us to reason that stable NHC-based radicals XIV should be synthetically accessible on one-electron reduction of the appropriate C2-arylated 1,3-imidazoli(ni)um salts. This ac- 

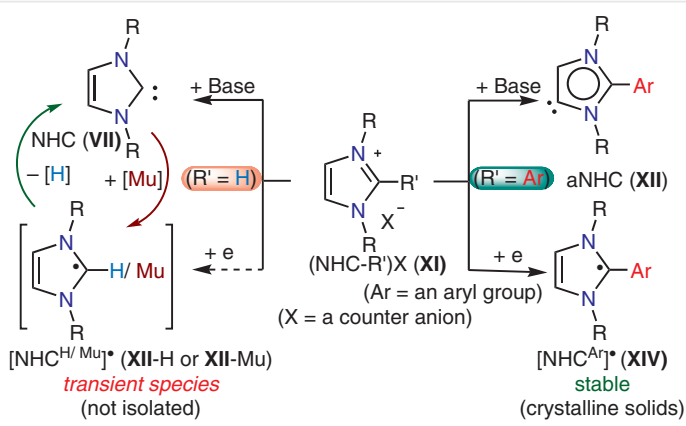

Scheme 4 Deprotonation of $\mathbf{X I}\left(\mathrm{R}=\right.$ aryl groups; $\mathrm{R}^{\prime}=\mathrm{H}$ or an aryl group) with a base to NHCs (VII) or MICs (XII). Reduction of $\mathbf{X I}\left(\mathrm{R}^{\prime}=\mathrm{H}\right)$ to an NHC via a transient radical XII-H. Reaction of VII with Mu to XIIMu. One-electron reduction of $\mathbf{X I}\left(\mathrm{R}^{\prime}=\mathrm{Ar}\right)$ to stable radicals $\mathbf{X I V}$

count summarizes recent advances, particularly from this laboratory, in NHC-based carbon-centered stable radicals chemistry.

\section{NHC-Monoradicals}

For the synthesis of desired C2-arylated precursors 3 , two protocols based on palladium ${ }^{36 e}$ and nickel ${ }^{36 b}$ catalysis have been developed in this laboratory. While the scope of palladium catalysis is limited to aryl iodides, nickel catalysis protocol is equally compatible with aryl bromides and iodides. Remarkably, bis-1,3-imidazoli(ni)um salts are also accessible by two-fold $\mathrm{C}-\mathrm{C}$ coupling of appropriate aryl dihalides with various NHCs (see below). The yield of reactions in most cases is more than $80 \%$. The product precipitates out in the employed solvent (o-xylene, THF, toluene or 1,4-dioxane) and can be readily extracted by simple filtration. No additional purification is required and the product can be used as such. Two typical examples with unsaturated (1a) and saturated (2) NHCs are shown in Scheme 5.

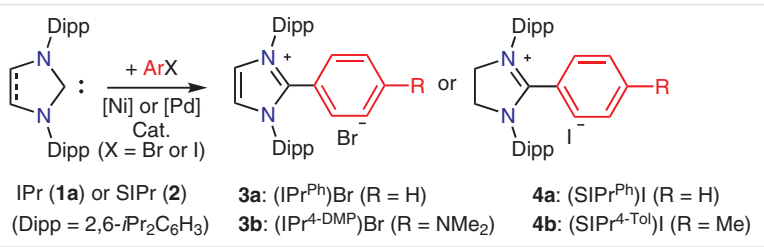

Scheme 5 Direct C2-arylation of NHCs $\mathbf{1 a}$ and $\mathbf{2}$ to $\mathbf{3 a}, \mathbf{3} \mathbf{b}, \mathbf{4 a}$, and $\mathbf{4 b}$

In contrast to the C2-protonated 1,3-imidazolium salts XI $\left(\mathrm{R}^{\prime}=\mathrm{H}\right)$, the CVs of C2-arylated 1,3-imidazoli(ni)um salts 3a, 3b $\left(E_{1 / 2}=-1.66 \mathrm{~V},-1.91 \mathrm{~V}\right)$ and 4a, $4 \mathbf{b}\left(E_{1 / 2}=-1.42 \mathrm{~V}\right.$, $-1.49 \mathrm{~V}$ vs. $\left.\mathrm{Fc}^{+} / \mathrm{Fc}\right)$ exhibit one-electron reduction at a very low potential (Figure 2). ${ }^{43}$ Note, the reduction potential for $\mathbf{3}$ and $\mathbf{4}$ is not only significantly lower compared with $\mathbf{X I - H}$ $\left(E_{1 / 2} \geq-2.3 \mathrm{~V}\right)$ but the process is also reversible. This indicates the accessibility and stability of the corresponding radicals.
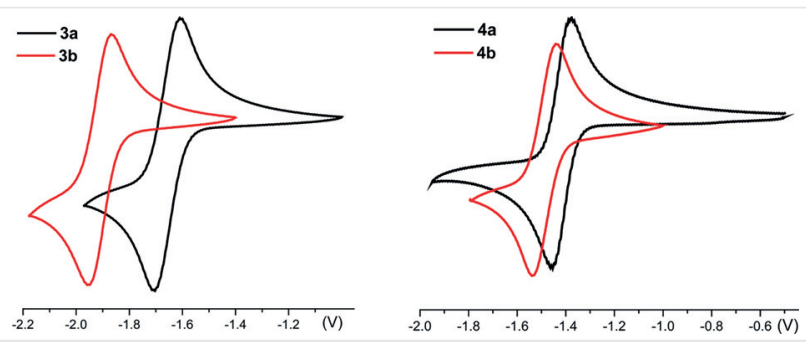

Figure 2 Cyclic voltammograms (CVs) of $\mathbf{3 a}, \mathbf{b}$ and $\mathbf{4 a} \mathbf{a}, \mathbf{b}$ (in $\mathrm{CH}_{3} \mathrm{CN} / \mathrm{nBu}_{4} \mathrm{NPF}_{6}, 100 \mathrm{mV} \mathrm{s}^{-1} \mathrm{vs}$. $\mathrm{Fc}^{+} / \mathrm{Fc}$ )

Indeed, the radicals $\left(\operatorname{IPr}^{\mathrm{Ph}}\right)^{\bullet}(\mathbf{5 a}),\left(\operatorname{IPr}^{4-\mathrm{DMP}}\right)^{\bullet}(\mathbf{5 b}),\left(\mathrm{SIPr}^{\mathrm{Ph}}\right)^{\cdot}$ (6a), and $\left(\mathrm{SIPr}^{4-\mathrm{Tol}}\right)^{\bullet}(\mathbf{6 b})$ are accessible as crystalline solids on chemical reduction of the corresponding cations $\mathbf{3 a , b}$ and $\mathbf{4 a , b}$ with $\mathrm{KC}_{8}$ (Scheme 6). Compounds 5 and $\mathbf{6}$ are deeply colored stable solids. ${ }^{43}$

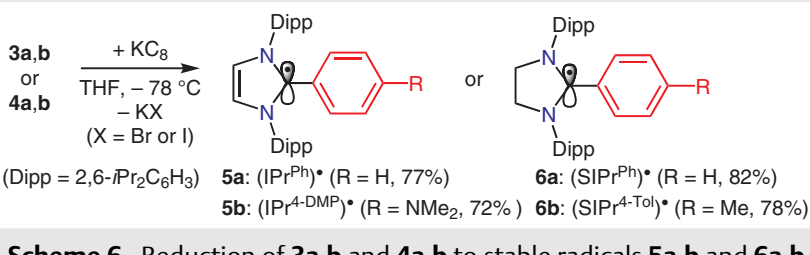

Freshly prepared samples of $\mathbf{5}$ and $\mathbf{6}$ were NMR silent but each of them exhibited a doublet EPR signal (see below), indicating their paramagnetic character. Attempts to grow single crystals of $\mathbf{5 a}$ and $\mathbf{5 b}$ for X-ray diffraction failed because they slowly decompose in solution to give the oxidized products. The unsaturated NHC (IPr) and its 1,3-imidazolium salts $(\mathbf{X I}, \mathbf{3})$ are $6 \pi$-electron aromates. The lonepair at the carbene carbon atom of IPr is the s-type orbital and does not take part in the $\pi$-system. The IPr-derived radicals $\mathbf{5}$ are $7 \pi$-electron systems. Thus, the loss of the aromaticity in the IPr-derived radicals $\mathbf{5 a} \mathbf{a}, \mathbf{b}$ may account for their low stability. This is however not the case with the SIPr-derivatives. Fortunately, the radicals $\mathbf{6}$ based on a saturated NHC (SIPr) are stable, and suitable single crystals can be

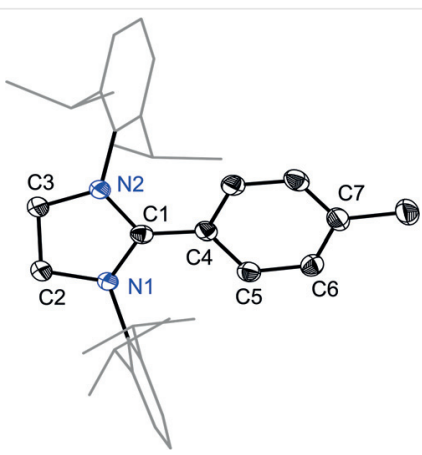

Figure 3 Solid-state molecular structure of the monoradical $\mathbf{6 b}$; $\mathrm{H}$ atoms are omitted for clarity 
grown from a saturated $n$-hexane solution. The solid-state molecular structures of $\mathbf{6 a}$ and $\mathbf{6 b}$ determined by X-ray diffraction are distinct from the free NHC (SIPr) and the corresponding 1,3-imidazolinium salts $\mathbf{4 a , b}$. A solid-state molecular structure of a typical radical $\mathbf{6 b}$ is shown in Figure 3.

The formation of free NHCs VII from their 1,3-imidazolium precursor $\mathbf{X I - H}$ is a formal two-electron reduction (Scheme 4), whereas one-electron reduction of $\mathbf{X I}-\mathrm{H}$ gives radicals $\mathbf{X I I}-\mathrm{H}$. The value of $\mathrm{C}-\mathrm{N}$ bond lengths and the $\mathrm{N}-\mathrm{C}-$ $\mathrm{N}$ bond angle in the free $\mathrm{NHC}(\mathbf{2})$ is clearly larger compared with the corresponding protonated precursor (Table 1 ).

Table 1 Selected Bond Lengths $(\AA)$ and Bond Angles $\left({ }^{\circ}\right)$ for the Free NHC (SIPr), Radical Precursors (4a and $\mathbf{4 b}$ ), and Radicals (6a and $\mathbf{6 b}$ )

\begin{tabular}{lllll}
\hline Compound & $\mathrm{C} 1-\mathrm{C} 4$ & $\mathrm{C} 4-\mathrm{C} 5$ & $\mathrm{C} 1-\mathrm{N} 1^{\mathrm{b}}$ & $\mathrm{N} 1-\mathrm{C} 1-\mathrm{N} 2$ \\
\hline $\mathrm{SIPr}(\mathbf{2})^{\mathrm{a}}$ & - & - & $1.346(2)$ & $105.0(1)$ \\
$\left(\mathrm{SIPP}{ }^{\mathrm{Ph}}\right) \mathrm{I}(\mathbf{4 a})$ & $1.474(2)$ & $1.395(2)$ & $1.329(2)$ & $111.8(2)$ \\
$\left(\mathrm{SIPr}^{\mathrm{Ph}}\right)^{\bullet}(\mathbf{6 a})$ & $1.398(5)$ & $1.430(5)$ & $1.410(4)$ & $107.7(3)$ \\
$\left.\left(\mathrm{SIPr}^{4-\mathrm{Tol}}\right)\right)^{(\mathbf{4 b})}$ & $1.477(4)$ & $1.390(4)$ & $1.333(4)$ & $111.8(3)$ \\
$\left(\mathrm{SIPr}^{4-\mathrm{Tol}}\right)^{\bullet}(\mathbf{6 b})$ & $1.406(2)$ & $1.429(2)$ & $1.405(1)$ & $108.5(1)$ \\
\hline
\end{tabular}

a Free NHC.

$\mathrm{b}$ The value is averaged.

An intermediate bond length and bond angle alteration trend can be expected for the respective radicals. Indeed, the $\mathrm{C} 1-\mathrm{N} 1 / \mathrm{N} 2$ bond lengths of $\mathbf{6 a}$ (av. 1.405(4) $\AA$ ) and $\mathbf{6 b}$ (av. 1.404(2) A) are considerably longer than those of 4a (av. $1.330(4) \AA$ ) and $\mathbf{4 b}$ (av. 1.329(4) $\AA$ ) as well as of $\operatorname{SIPr}(\mathbf{2})$ (av. $1.346(2) \AA) .{ }^{44}$ The N1-C1-N2 bond angle of $\mathbf{6 a}\left(108.9(3)^{\circ}\right)$ and $\mathbf{6 b}\left(108.5(9)^{\circ}\right)$ is intermediate between the free carbene $\operatorname{SIPr}\left(105.0(1)^{\circ}\right)^{44}$ and the imidazolinium salts $(2-\mathrm{H})^{+}$ $\left(114.6(4)^{\circ}\right), \mathbf{4 a} \cdot\left(111.8(1)^{\circ}\right)$ or $\mathbf{4 b}\left(111.0(1)^{\circ}\right)$. Similarly, the C1-C4 bond length in 6a (1.398(5) $\AA$ ) and $\mathbf{6 b}(1.406(2) \AA)$ is shortened considerably in comparison with $\mathbf{4 a}(1.474(2) \AA)$ and $\mathbf{4 b}(1.477(4) \AA)$. Some bond lengths alteration across $\mathrm{C}_{\text {ipso }}-\mathrm{C}_{\text {ortho }}$ bonds of the aryl (Ph or 4-Tol) substituent of $\mathbf{6 a}, \mathbf{b}$ is also observed in comparison with $\mathbf{4 a} \mathbf{a}, \mathbf{b}$. The structural parameters are fully consistent with the radical character of $\mathbf{6 a}, \mathbf{b}$ and the partial delocalization of the unpaired electron over the aryl substituent at the carbene carbon atom.

The localized Mülliken atomic spin densities (see Figure 4 for $\mathbf{6 b}$ ) clearly reveal that the unpaired electron in $\mathbf{5}$ and $\mathbf{6}$ is mainly located on the carbene carbon atom (37-45\%). In addition, there are considerable spin densities on the ortho(19-23\%) and para- (19-29\%) carbon atoms of the aryl group, but only $8-11 \%$ on the ring nitrogen atoms. This suggests that the radicals $\mathbf{5}$ and $\mathbf{6}$ are stabilized by delocalization of the unpaired electron on the C2-aryl substituent. The EPR spectroscopic studies clearly support the paramagnetic nature of $\mathbf{5}$ and $\mathbf{6}$. The room-temperature EPR spectra of $\mathbf{5}$ and $\mathbf{6}$ in THF show a doublet, which is a characteristic

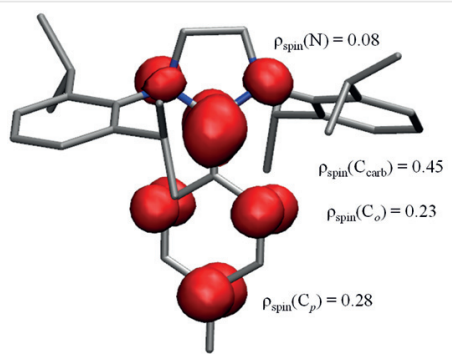

Figure 4 Calculated spin densities (isovalue 0.003 a.u.) and Mulliken spin density $\left(\rho_{\text {spin }}\right)$ numbers at the BP86+D3(B])/def2-TZVPP//BP86$\mathrm{D} 3(\mathrm{BJ}) /$ def2-SVP level of theory for $\mathbf{6} \mathbf{b}$; $\mathrm{H}$ atoms are omitted for clarity

of monoradical species (Figure 5). The doublet displays couplings with two nitrogen atoms and several hydrogen atoms of the aryl substituent. The calculated hyperfine coupling $(h f c)$ constants at the PBE0/EPR-II//BP86+D3(BJ)/def2SVP level of theory for $\mathbf{6 a}$ were found to be $A_{\text {iso }}\left({ }^{14} \mathrm{~N}\right)=6.08$, 5.71; $\mathrm{A}_{\text {iso }}\left({ }^{1} \mathrm{H}\right)=-16.12\left({ }_{\text {ortho }}-\mathrm{Ph}\right), 7.27\left({ }_{\text {meta }}-\mathrm{Ph}\right),-20.76\left({ }_{\text {para }}-\mathrm{Ph}\right)$. The significant low $A_{\text {iso }}\left({ }^{14} \mathrm{~N}\right)$ value $(4.10-6.09)$ for $\mathbf{5 a}, \mathbf{b}$ and $\mathbf{6 a}, \mathbf{b}$ is in good agreement with the computed spin density at the nitrogen atoms.
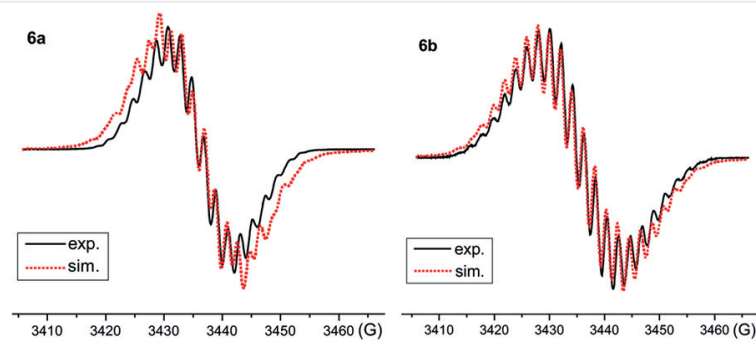

Figure $\mathbf{5}$ Experimental and simulated EPR spectra of $\mathbf{6 a}$ and $\mathbf{6 b}$

After having isolated the monoradicals $\mathbf{5}$ and $\mathbf{6}$, one obvious quest was to probe the feasibility of stable species featuring more than one unpaired electron. The initial challenge was to access suitable starting materials.

\section{NHC-Diradical(oid)s}

Compounds featuring two unpaired electrons are called biradicals, diradicals, or diradicaloids, depending on the interaction between two spin dipoles. The presence of two unpaired electrons adds additional complexity to the structure and properties of these entities. The double carbenylation of 1,4-dihaloarenes with NHCs under nickel catalysis affords the desired dicationic species $\left[(\mathrm{NHC})\left(\mathrm{C}_{6} \mathrm{H}_{4}\right)_{n}(\mathrm{NHC})\right](\mathrm{X})_{2}(\mathrm{X}=\mathrm{Br}$ or I) (Scheme 7). Salts 7-9 can be isolated as white or pale-yellow crystalline solids in good to excellent ( $>80 \%$ ) yields. Both unsaturated (1a and 1b $)^{45}$ as well as saturated $(\mathbf{2})^{46}$ NHCs can be used. 

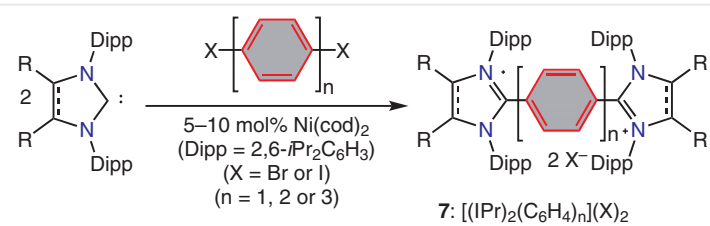

1a: $\operatorname{IPr}(\mathrm{R}=\mathrm{H})$

2: $\operatorname{SIPr}(R=H, H)$

$(\mathrm{n}=1(7 \mathrm{a}, 87 \%), 2(7 \mathrm{~b}, 93 \%), 3(7 \mathrm{c}, 66 \%))$

8: $\left.\left[(\mathrm{Me}-\mathrm{IPr})_{2}\left(\mathrm{C}_{6} \mathrm{H}_{4}\right)_{3}\right)\right](\mathrm{I})_{2}(72 \%)$ 9: $\left[(\mathrm{SIPr})_{2}\left(\mathrm{C}_{6} \mathrm{H}_{4}\right)_{\mathrm{n}}\right](\mathrm{X})_{2}$

$(n=1(9 a, 81 \%), 2(9 b, 71 \%), 3(9 c, 68 \%))$

Scheme 7 Two-fold carbenylation of 1,4-dihaloarenes with NHCs to bis(1,3-imidazoli(ni)um) salts $(\mathrm{NHC})\left(\mathrm{C}_{6} \mathrm{H}_{4}\right)_{n}(\mathrm{NHC})$

The CVs of compounds $\left[(\operatorname{IPr})_{2}\left(\mathrm{C}_{6} \mathrm{H}_{4}\right)\right](\mathrm{Br})_{2} \quad \mathbf{7 a}$ and $\left[(\operatorname{IPr})_{2}\left(\mathrm{C}_{6} \mathrm{H}_{4}\right)_{2}\right](\mathrm{Br})_{2} \mathbf{7 b}$ (Figure 6) exhibit two one-electron reductions in the -1.04 to $-1.51 \mathrm{~V}$ region..$^{45}$ The first reversible one-electron reduction at $E_{1 / 2}=-1.04 \mathrm{~V}(\mathbf{7 a})$ and $E_{1 / 2}$ $=-1.37 \mathrm{~V}(\mathbf{7 b}) \mathrm{vs}$. $\mathrm{Fc} / \mathrm{Fc}^{+}$corresponds to a radical cation, which undergoes a second reduction at $E_{1 / 2}=-1.29 \mathrm{~V}(\mathbf{7 a})$ and $E_{1 / 2}=-1.51 \mathrm{~V}(\mathbf{7 b})$ to give the corresponding neutral species. A similar trend can also be seen for the derivatives 9a and $\mathbf{9 b}$ based on the saturated NHC, $\operatorname{SIPr}(\mathbf{2}) .{ }^{46}$ Nonetheless, both redox events in $\mathbf{9 a}\left(E_{1 / 2}=-0.80\right.$ and $\left.-0.95 \mathrm{~V}\right)$ and $\mathbf{9 b}\left(E_{1 / 2}=-1.04\right.$ and $\left.-1.28 \mathrm{~V}\right)$ occur at a lower potential compared with $\mathbf{7 a}$ and $\mathbf{7 b}$. Similarly, CVs of compounds featuring a terphenylene spacer, $\mathbf{7 c}, \mathbf{8}$, and $\mathbf{9 c}$ also exhibit two cycles consistent with two one-electron (quasi)reversible redox processes. ${ }^{47}$ Masuda and co-workers reported twoelectron reduction of a closely related system $\left[(\mathrm{SIPr}) \mathrm{C} \equiv \mathrm{C}\left(\mathrm{C}_{6} \mathrm{H}_{4}\right) \mathrm{C} \equiv \mathrm{C}(\mathrm{SIPr})\right](\mathrm{Br})_{2}$ and isolated a stable cumulene $\left[(\mathrm{SIPr})=\mathrm{C}=\mathrm{C}=\left(\mathrm{C}_{6} \mathrm{H}_{4}\right)=\mathrm{C}=\mathrm{C}=(\mathrm{SIPr})\right]{ }^{48}$ Moreover, Bertrand et al. also reported ${ }^{30 e, 30 f}$ stable cumulenes as well as mixedvalence compounds derived from CAACs that exhibit considerable open-shell character. Very recently, some mixedvalence systems based on carbene-pyrylium/pyridinium hybrids have been also reported. ${ }^{49}$

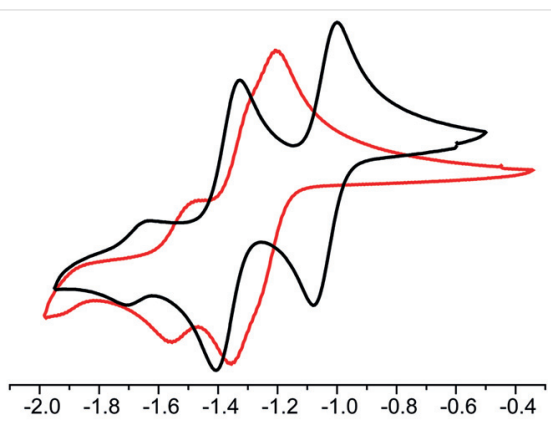

Figure 6 Cyclic voltammograms of $\left[(\mathrm{IPr})_{2}\left(\mathrm{C}_{6} \mathrm{H}_{4}\right)\right](\mathrm{Br})_{2} 7 \mathbf{7 a}$ (black line) and $\left[(\mathrm{IPr})_{2}\left(\mathrm{C}_{6} \mathrm{H}_{4}\right)_{2}\right](\mathrm{Br})_{2} \mathbf{7 b}$ (red line) in $\mathrm{CH}_{3} \mathrm{CN} / \mathrm{Bu}_{4} \mathrm{NPF}_{6}$ (vs. $\mathrm{Fc} / \mathrm{Fc}+$ ) in $\mathrm{V}$

As indicated by the cyclic voltammetry studies, twoelectron reduction of 7-9 with a suitable reagent should lead to the formation of the corresponding neutral compounds. Indeed, treatment of 7-9 with $\mathrm{KC}_{8}$ afforded expected compounds 10-12 in good to excellent yields (Scheme
8). Ether open-shell (singlet or triplet) diradical (A) or closed-shell quinoid (B) resonance forms can be drawn to describe the structure of compounds 10-12. The weight of each form depends on the interaction between the unpaired electrons, which, for a perfect quinoidal structure, results in a two-center-two-electron covalent bond formation at the expense of an aromatic sextet(s). Compounds 10-12 can be regarded as NHC-analogues of $\mathbf{T H}, \mathbf{C H}$, and MH (Scheme 2). Therefore, it is logical to compare and analyze the structure and properties of 10-12 with these classical HCs.

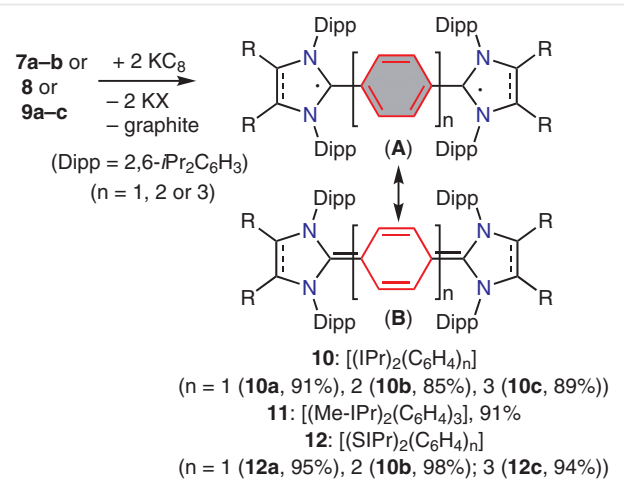

Scheme $8 \mathrm{KC}_{8}$ reduction of $7, \mathbf{8}$, and 9 to radical hydrocarbons 10,11 , and 12 , respectively. Diradical $(A)$ and quinoidal $(B)$ resonance forms of 10-12

\subsection{NHC Analogues of Thiele's Hydrocarbon (TH)}

The TH $(1904)^{16}$ and $\mathbf{C H}(1907)^{17}$ were already reported in the beginning of 20th century; it was, however, only in 1986 when Montgomery et al. successfully solved the solidstate molecular structures of these highly reactive species by single-crystal X-ray diffraction. ${ }^{19}$ This provided a direct comparison of the $\mathrm{C}-\mathrm{C}$ bond length of the central phenylene ring and consequently settled the issues associated with 'the Biradical Paradox'. It should however be noted that the purification of $\mathbf{T H}, \mathbf{C H}$, and related compounds is extremely difficult and the presence of even 0.01\% monoradical impurity results in a doublet EPR signal. This may mask the weak intensity triplet expected for a triplet diradical, if it exists in a thermal equilibrium with an openshell singlet diradical. ${ }^{50}$ Structural parameters of $\mathbf{~ T H}$ and $\mathbf{C H}$ along with the NHC-derivatives $\mathbf{1 0 a}, \mathbf{1 0 b}$ and $\mathbf{1 2 a}, \mathbf{1 2 b}$, are given in Table 2. The calculated bond lengths and bond angles for the respective closed-shell (CS) singlet and openshell triplet $(\mathrm{T})$ are also summarized in Table 2. As can be seen from these data, the bond length alteration (BLA) for the phenylene bridge in NHC-derivatives 10a and 12a is comparable to that of $\mathbf{T H}(0.10 \AA)$. Therefore, the formation of 10a and 12a is accompanied by the loss of benzenoid structure of 7a and 9a. Experimental structures of 10a and 12a determined by X-ray diffraction show close resemblance with those calculated for closed-shell systems. In- 
deed, a pure sample of 12a is EPR silent and exhibits wellresolved ${ }^{1} \mathrm{H}$ and ${ }^{13} \mathrm{C}$ NMR signals for the NHC and $\left(\mathrm{C}_{6} \mathrm{H}_{4}\right)$ units. As described by Nakano, ${ }^{51}$ the open-shell nature of a system can be expressed in terms of its diradical character ( $y=0$ for the close-shell and $y=1$ for the pure singlet diradical). The diradical character for compound 10a and 12a was calculated to be zero $(y=0)$ and thus they are closedshell species. The estimated value for the TH $(y=0.31)$ is, however, considerably higher. ${ }^{50}$ While the ground state for both 10a and 12a is a closed-shell singlet, the calculated singlet-triplet energy gap (ca. $27 \mathrm{kcal} / \mathrm{mol}$ ) is however rather small.

\subsection{NHC Analogues of Chichibabin's Hydrocarbon $(\mathrm{CH})$}

The BLA for compounds 10b (Figure 7) and 12b (0.08 $\AA$ ), NHC-analogues of the $\mathbf{C H}$, is smaller compared with 10a and 12a $(0.10 \AA)$, but larger with respect to that of $\mathbf{C H}$ (0.05 $\AA$ ). The calculated diradical character for $\mathbf{1 0 b}(y=0.41$ at B3LYP/def2-SVP level of theory) and 12b $(y=0.43$ at B3LYP/def2-TZVPP level of theory) is higher than that of 10a and 10b but it is considerably lower when compared with that of $\mathbf{C H}(y=0.72)$. The singlet-triplet energy gap of $10.7 \mathrm{kcal}$ calculated at B3LYP/def2-SVP for $\mathbf{1 0 b}$ and $\mathbf{1 2 b}$ is smaller than their monophenylene counterparts 10a and 12a (ca. $27 \mathrm{kcal} / \mathrm{mol}$ ).

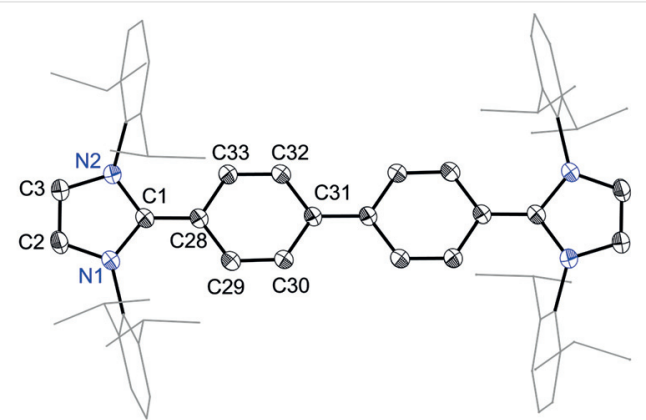

Figure 7 Molecular structure of $\mathbf{1 0 b}$; $\mathrm{H}$ atoms are omitted for clarity

Table 2 Selected Bond Lengths ( $(\AA)$ and Angles $\left({ }^{\circ}\right)$ Determined by X-ray Diffraction for the Precursors (7a, 7b, 9a, 9b), NHC-Hydrocarbons (10a, 10b, 12a, 12b), Thiele's (TH) and Chichibabin's (CH) HCs; ${ }^{19}$ and Calculated (B3LYP/def2-SVP) for 10a,b and 12a,b in Close-Shell (CS) and Triplet (T) Ground States.

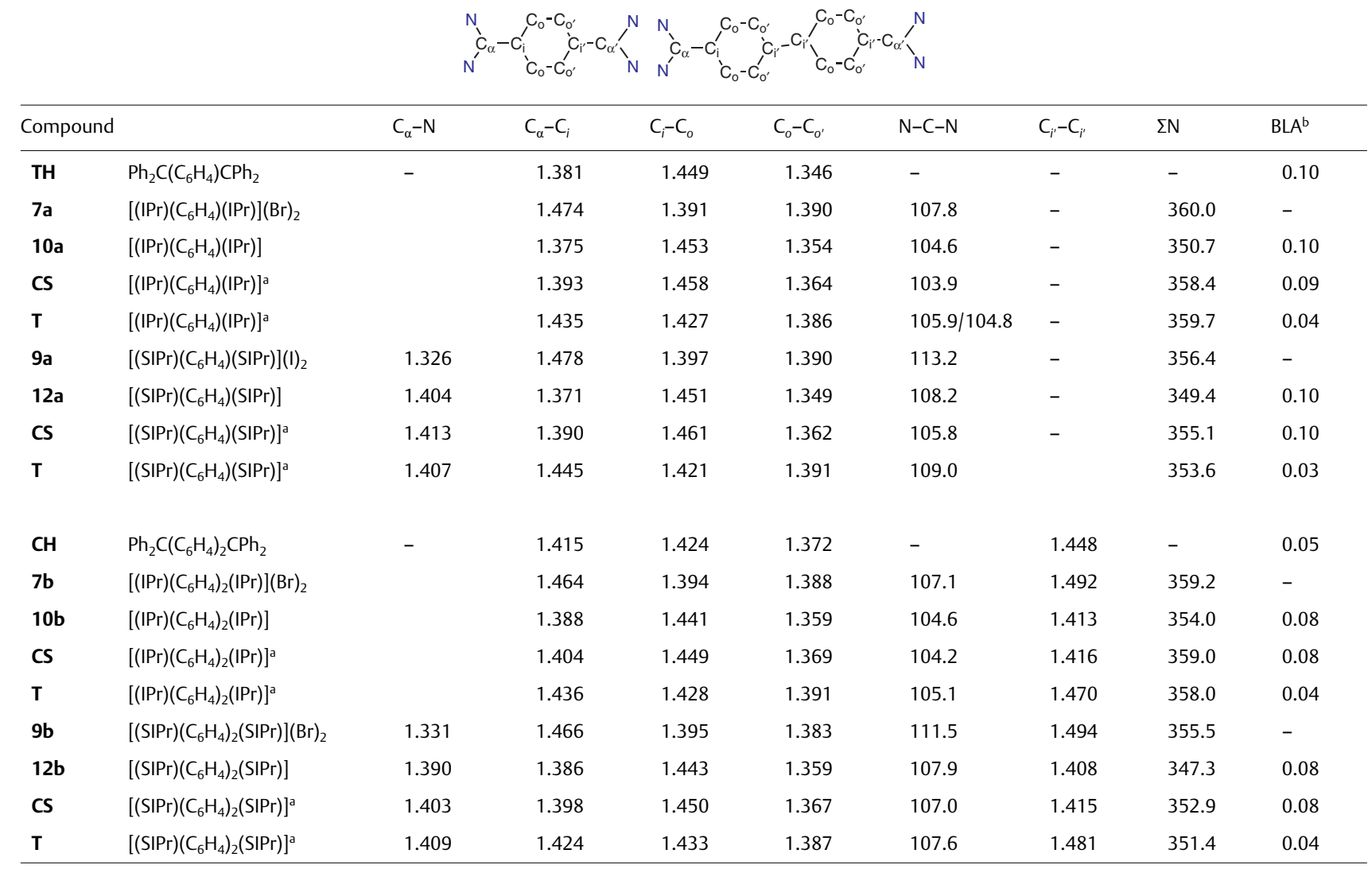

${ }^{a}$ Calculated for closed-shell (CS) and triplet (T) states.

${ }^{\mathrm{b}}$ Bond length alteration $(\mathrm{BLA})=\left(\mathrm{C}_{i}-\mathrm{C}_{0}-\mathrm{C}_{0}-\mathrm{C}_{0^{\prime}}\right)$. 
This suggests that compounds $\mathbf{1 0 b}$ and $\mathbf{1 2 b}$ should be considered as singlet diradicaloids. Multireference CASSCF(2,2)+NEVPT2/def2-SVP calculations for model systems $\mathbf{1 0 b}-\mathbf{M}$ and 12b-M (where Dipp groups of $\mathbf{1 0 b}$ and $\mathbf{1 2 b}$ are replaced by methyl groups) also support their diradicaloid character. The extent of pyramidalization of the nitrogen atom (Table 2) of the 1,3-imidazol(in)e rings can also account for the quinoid character of $\mathbf{1 0 a}, \mathbf{b}$ and $\mathbf{1 2 a}, \mathbf{b}$. As indicated by the sum of the angles at the nitrogen atom $(\Sigma \mathrm{N})$, the nitrogen atoms in the precursors 7a $\left(\Sigma \mathrm{N}=360.0^{\circ}\right)$ and 9a $\left(\Sigma \mathrm{N}=359.2^{\circ}\right)$ containing the unsaturated $\mathrm{NHC}(\mathrm{IPr})$ are planar. One of the nitrogen atoms in 10a $\left(\Sigma \mathrm{N}=350.7^{\circ}\right)$ and 12a $\left(\Sigma \mathrm{N}=354.0^{\circ}\right)$ is, however, pyramidalized. A rather large pyramidalization in the former suggests its higher quinoid character compared with the latter. A similar trend can also be seen in compounds $\mathbf{1 0 b}$ and $\mathbf{1 2 b}$ derived from the saturated NHC (SIPr).

\subsection{NHC Analogues of Müller's Hydrocarbon (MH)}

The $\mathrm{MH}^{21}$ with a terphenylene (III, $n=3$, Scheme 3) bridge has higher diradical character compared to TH and CH. This can be rationalized according to Clar's aromatic sextet rule ${ }^{20}$ as the OS diradical form IIIa preserves three aromatic rings. Consequently, the $\mathbf{M H}$ is extremely reactive and it remains a challenging task to obtain pure samples for reliable measurements. Nonetheless, stable analogues of MH have been reported by using appropriate synthetic approaches (see above). The exceptional stability of $\mathbf{1 0 a}, \mathbf{b}$ and 12a,b prompted us to prepare stable NHC-analogues of $\mathrm{MH}$. Fortunately, the nickel catalysis protocol with a slightly higher loading (10 mol\%) gave access to the desired dications 7c, 8, and 9c ( $n=3$; Scheme 7$)$ using three different NHCs. Consistent with the CVs of 7c, 8, and 9c, their twoelectron reduction with $\mathrm{KC}_{8}$ afforded compounds 10c, 11, and 12c $(n=3$; Scheme 8$)$ as stable crystalline solids after workup. Structural parameters (Table 3 ) of 10c, 11, and 12c (Figure 8) clearly reveal the enhanced weight of the openshell diradical form compared with related $\mathrm{CH}$-analogues (10b and 12b) (Table 2). The BLA is in the 0.05-0.07 $\AA$ range for the central and terminal phenylene rings of the ter-

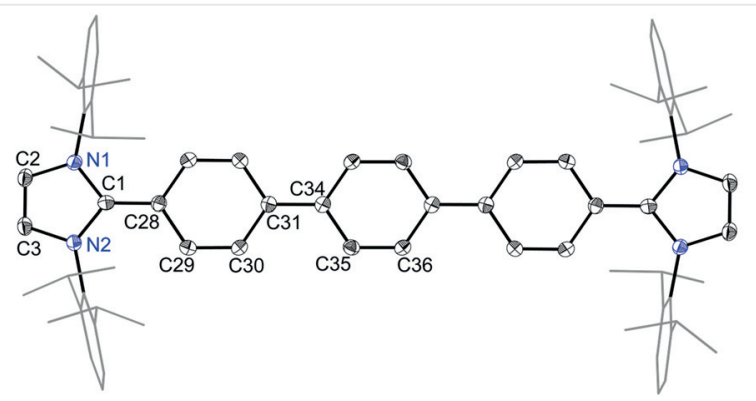

Figure 8 Solid-state molecular structure of 12c; $\mathrm{H}$ atoms are omitted for clarity phenylene unit. This suggests that compounds 10c, 11, and 12c still have a considerable contribution of the quinoid resonance form, which is nonetheless smaller compared to that of 10a,b and 12a,b.

The BLA calculated for the RB3LYP-optimized structures for singlet diradicaloids was found to be similar to those of the solid-state data of 10c, 11, and 12c obtained by X-ray diffraction (Table 3 ). As expected, elongation of the spacersize leads to enhancement of the diradical character of $\mathbf{1 0 c}$ (0.65), 11 (0.64), and 12c (0.65). The diradical character calculated for the $\mathbf{T H}(0.28), \mathbf{C H}(0.59)$, and $\mathbf{M H}(0.82)$ at the same level of theory (PUHF/6-311G*) indicate that the replacement of the $\mathrm{Ph}_{2} \mathrm{C}$ moiety with an NHC leads to the reduction of diradical character. This may be due to the difference in the delocalization of frontier molecular orbitals concerning the diradical character.

Table 3 Selected Bond Lengths $(\AA)$ and Angles $\left({ }^{\circ}\right)$ Determined for 7c, $9 c, 10 c$, and 12 c by $X$-ray Diffraction

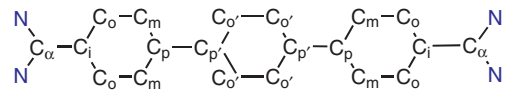

\begin{tabular}{ccccccl}
\hline & $C_{i}-C_{o}$ & $C_{o}-C_{m}$ & $C_{p}-C_{p^{\prime}}$ & $C_{p^{\prime}}-C_{o^{\prime}}$ & $C_{o^{\prime}}-C_{o^{\prime}}$ & $B^{2} A^{a}$ \\
\hline $\mathbf{7 c}$ & 1.392 & 1.390 & 1.482 & 1.396 & 1.390 & 0.00 \\
$\mathbf{1 0 c}$ & 1.436 & 1.364 & 1.431 & 1.425 & 1.367 & $0.07[0.06]^{c}$ \\
$\mathbf{9 c}$ & 1.398 & 1.387 & 1.481 & 1.396 & 1.389 & 0.01 \\
$\mathbf{1 2} \mathbf{c}^{\mathrm{b}}$ & 1.436 & 1.364 & 1.433 & 1.425 & 1.372 & $0.07[0.05]^{\mathrm{c}}$ \\
& $(1.435)$ & $(1.369)$ & $(1.434)$ & $(1.429)$ & $(1.370)$ & $0.07[0.06]^{\mathrm{c}}$ \\
\hline
\end{tabular}

a Bond length alteration (BLA) $=\left(C_{i}-C_{0}-C_{0}-C_{m}\right)$. The values for $C_{i}-C_{0}, C_{0}-C_{m}$, and $\mathrm{C}_{p^{\prime}}-\mathrm{C}_{0^{\prime}}$ are averaged.

b $12 c$ contains two molecules in the asymmetric unit (values of the second molecule).

c $\mathrm{BLA}$ for the middle phenylene ring $\left[\mathrm{C}_{p^{\prime}}-\mathrm{C}_{0^{\prime}}-\mathrm{C}_{0^{\prime}}-\mathrm{C}_{0^{\prime}}\right]$.

The singlet-triplet energy gap for 10c (7.24), 11 (7.60), and $12 \mathrm{c}(7.40 \mathrm{kcal} / \mathrm{mol})$ is significantly smaller compared to the related monophenylene 10a (38.28) and biphenylene $12 a(18.56 \mathrm{kcal} / \mathrm{mol})$ derivatives at the same level of theory. While this implies the singlet ground state for compounds 10c, 11, and 12c, the triplet state may be populated to some extent at moderate temperature given a relatively small $\Delta E_{\mathrm{S}-\mathrm{T}}$. Indeed, the EPR spectra of 10c, 11, and 12c (Figure 9a) each exhibit a half-field signal at $298 \mathrm{~K}$ for the forbidden $\Delta \mathrm{M}_{\mathrm{s}}=2$ transition, a characteristic of triplet diradicals. The calculated spin-density distribution maps for the singlet state of 10c, 11, and 12c (Figure 9b) suggest that the unpaired electron density is mainly located at the carbenecarbon atoms and the terminal phenylene rings.

\section{Conclusion and Outlook}

Synthetic access to fundamentally unique stable radicals and diradicaloids based on classical NHCs has been ac- 
a)

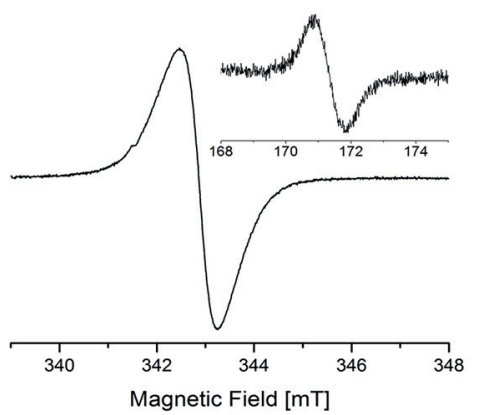

b)

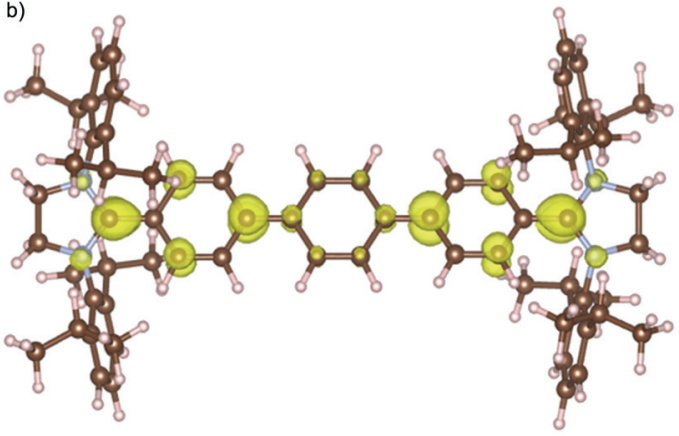

Figure 9 (a) Solid-state X-band EPR spectrum of 12c at $298 \mathrm{~K}$ with inset showing the half-field signal. (b) Odd-electron density map (yellow mesh represents the isosurface with the contour value of 0.003 a.u) of $12 c$

complished. The results reveal the impact of an aryl substituent at the C2-position of NHCs on the stability of derived radicals. Most strikingly, the desired starting materials can be readily prepared in almost quantitative yield by the direct C2-arylation of commercially available NHCs either under nickel or palladium catalysis. The methodology is straightforward and both the pre-catalysts $\mathrm{Ni}(\mathrm{COD})_{2}$ and $\operatorname{Pd}_{2}(\mathrm{dba})_{3}$ are commercially available. As the nature of aryl substituents has a direct influence on the stability and property of the derived radicals, further efforts to expand the scope of C2-arylation strategy would be valuable. Direct C2-arylation of air-stable 1,3-imidazoli(ni)um salts, instead of free NHCs, to the desired C2-arylated products is more appealing as it excludes the synthesis and handling of airsensitive carbenes. This obviously relies on the development of new catalytic protocols, which is also important to broaden the scope of this transformation to different NHCs with variable steric and electronic features.

Systematic investigations are required to identify the key parameters that direct the physical (optical, electronic, magnetic) properties of NHC-based radicals and diradical(oid)s. Instead of simple aryl groups, the use of other $\pi$ conjugated substituents at the C2-position of NHCs is an appropriate means to further enhance the stability as well as to control the properties of derived radicals. In this con- text, furan, thiophene, pyridine, pyrazine, cyclopentadiene, and other heterocycles containing a heavier main-group element ( $\mathrm{P}, \mathrm{As}$, Se or Te) are interesting candidates.

Diradicaloids are considered as very promising singletfission (SF) materials for their application in organic solar cells. ${ }^{52}$ Molecular systems with too small $\Delta E_{\mathrm{S}-\mathrm{T}}$ gaps and those with triplet ground states are not suitable for efficient SF because they have large deviation from $2 \mathrm{E}(\mathrm{T} 1)=$ $E(S 1)$, leading to high energy loss and slow SF rate. ${ }^{52 a, 53} \mathrm{Be}-$ cause of the open-shell singlet ground state and a small singlet-triplet gap, NHC-based diradicaloids hold promise for the design of SF materials. A facile access to stable NHC-diradicaloids is expected to prompt further progress in synthesis, physicochemical measurement, and theoretical analysis on the open-shell compounds with variable diradical characters. Innovative NHC-radical(oid)s based on polycyclic aromatic hydrocarbon (PAH) spacers (e.g., naphthalene, anthracene, pyrene, and other acenes) are important targets we are working on.

NHC-diradicaloids are also interesting as candidates for open-shell (non)linear optical materials. ${ }^{22,54}$ Future targets include mixed-valence (MV) compounds, high-spin (triand polyradicals) molecules, and non-Kekulé diradicals based on NHC and other singlet carbene frameworks. The incorporation of NHC-based radicals in mechanically interlocked molecules (MIMs) has enormous potential in supramolecular chemistry and materials science and thus is worth pursuing. Among MIMs, the synthesis of catenanes and rotaxanes containing NHC-based pro-radical frameworks is under way in this laboratory.

\section{Funding Information}

Funding from the Deutsche Forschungsgemeinschaft (GH 129/4) is gratefully acknowledged.

\section{Acknowledgment}

I am very thankful to my current and former co-workers whose names appear in the corresponding citations for their valuable contributions. I am grateful to my collaborators Dr. Diego M. Andrada (Universität des Saarlandes), Dr. Maurice van Gastel (MPI für Kohlenforschung Mülheim), and Prof. Dr. Masayoshi Nakano (Osaka University, Japan) for their contributions. I express my gratitude to Professor Dr. Norbert Mitzel for his generous support and encouragement.

\section{References}

(1) Renaud, P.; Sibi, M. P. Radicals in Organic Synthesis; Wiley-VCH: Weinheim, 2008.

(2) (a) Halliwell, B.; Gutteridge, J. M. C. Free Radicals in Biology and Medicine, 5th ed; Oxford University Press: UK, 2015. (b) Chatgilialoglu, C.; Studer, A. Encyclopedia of Radicals in Chemistry, Biology and Materials; Wiley-VCH: Weinheim, 2012. (c) Berliner, L. J. Spin Labeling: A Modern Perspective, In Stable 
Radicals; John Wiley \& Sons: Hoboken, 2010, 521-534. (d) Goldstein, S.; Samuni, A. Biologically Relevant Chemistry of Nitroxides, In Stable Radicals; John Wiley \& Sons: Hoboken, 2010, 567-576.

(3) (a) Bielawski, C. W.; Grubbs, R. H. Prog. Polym. Sci. 2007, 32, 129. (b) Tomlinson, E. P.; Hay, M. E.; Boudouris, B. W. Macromolecules 2014, 47, 6145.

(4) Newcomb, M. Radicals, In Reactive Intermediate Chemistry; Moss, R. A.; Platz, M. S.; Jones, M. Jr., Ed.; John Wiley \& Sons: Hoboken, 2005, 121-163.

(5) The term 'stable' refers to a molecular entity that persists for many days in solution and can be isolated (or stored) at room temperature $\left(25^{\circ} \mathrm{C}\right)$ under an inert gas (nitrogen or argon) atmosphere without appreciable decomposition.

(6) (a) Hicks, R. G. Can. J. Chem. 2004, 82, 1119. (b) Hicks, R. G. Stable Radicals: Fundamentals and Applied Aspects of Odd-Electron Compounds; John Wiley \& Sons Ltd: Weinheim, 2010. (c) Sloan, G. J.; Vaughan, W. R. J. Org. Chem. 1957, 22, 750.

(7) (a) Ai, X.; Chen, Y.; Feng, Y.; Li, F. Angew. Chem. Int. Ed. 2018, 57, 2869. (b) Wilcox, D. A.; Agarkar, V.; Mukherjee, S.; Boudouris, B. W. Annu. Rev. Chem. Biomol. Eng. 2018, 9, 83. (c) Wang, Y.; Frasconi, M.; Stoddart, J. F. ACS Cent. Sci. 2017, 3, 927.

(8) (a) Salem, L.; Rowland, C. Angew. Chem. Int. Ed. Engl. 1972, 11, 92. (b) Borden, W. T. Diradicals - A Fifty Year Fascination, In The Foundations of Physical Organic Chemistry: Fifty Years of the James Flack Norris Award, Vol. 1209; American Chemical Society: Washington, DC, 2015, p 251-303. (c) Abe, M. Chem. Rev. 2013, 113, 7011.

(9) (a) Zeng, Z.; Shi, X.; Chi, C.; Lopez Navarrete, J. T.; Casado, J.; Wu, J. Chem. Soc. Rev. 2015, 44, 6578. (b) Ratera, I.; Veciana, J. Chem. Soc. Rev. 2012, 41, 303. (c) Hu, X.; Wang, W.; Wang, D.; Zheng, Y. J. Mater. Chem. C 2018, 6, 11232.

(10) (a) Suga, T.; Nishide, H. Rechargeable Batteries Using Robust but Redox Active Organic Radicals, In Stable Radicals; John Wiley \& Sons, Ltd: Weinheim, 2010, 507-518. (b) Luo, J.; Hu, B.; Debruler, C.; Liu, T. L. Angew. Chem. Int. Ed. 2018, 57, 231. (c) Kim, D. J.; Hermann, K. R.; Prokofjevs, A.; Otley, M. T.; Pezzato, C.; Owczarek, M.; Stoddart, J. F. J. Am. Chem. Soc. 2017, $139,6635$.

(11) Muench, S.; Wild, A.; Friebe, C.; Häupler, B.; Janoschka, T.; Schubert, U. S. Chem. Rev. 2016, 116, 9438.

(12) (a) Beeson, T. D.; Mastracchio, A.; Hong, J.-B.; Ashton, K.; MacMillan, D. W. C. Science 2007, 316, 582. (b) Studer, A.; Curran, D. P. Angew. Chem. Int. Ed. 2016, 55, 58.

(13) Gomberg, M. J. Am. Chem. Soc. 1900, 22, 757.

(14) (a) Alcon, I.; Bromley, S. T. RSC Adv. 2015, 5, 98593. (b) Tidwell, T. T. Triarylmethyl and Related Radicals, In Stable Radicals; John Wiley \& Sons, Ltd: Weinheim, 2010, 1-3. (c) Veciana, J.; Ratera, I. Polychlorotriphenylmethyl Radicals: Towards Multifunctional Molecular Materials, In Stable Radicals; John Wiley \& Sons, Ltd: Weinheim, 2010, 33-76.

(15) (a) Jung, Y.; Head-Gordon, M. ChemPhysChem 2003, 4, 522. (b) Seierstad, M.; Kinsinger, C. R.; Cramer, C. J. Angew. Chem. Int. Ed. 2002, 41, 3894. (c) Abe, M.; Ye, J.; Mishima, M. Chem. Soc. Rev. 2012, 41, 3808. (d) Grützmacher, H.; Breher, F. Angew. Chem. Int. Ed. 2002, 41, 4006. (e) Breher, F. Coord. Chem. Rev. 2007, 251, 1007.

(16) Thiele, J.; Balhorn, H. Ber. Dtsch. Chem. Ges. 1904, 37, 1463.

(17) Tschitschibabin, A. E. Ber. Dtsch. Chem. Ges. 1907, 40, 1810.

(18) (a) Kanzaki, Y.; Shiomi, D.; Sato, K.; Takui, T. J. Phys. Chem. B 2012, 116, 1053. (b) McConnell, H. M. J. Chem. Phys. 1960, 33, 1868.
(19) Montgomery, L. K.; Huffman, J. C.; Jurczak, E. A.; Grendze, M. P. J. Am. Chem. Soc. 1986, 108, 6004.

(20) (a) Solà M.; Front. Chem.; 2013, 1; DOI: 10.3389/fchem.2013.00022 . (b) Clar, E. The Aromatic Sextet, In Mobile Source Emissions Including Policyclic Organic Species; Rondia, D.; Cooke, M.; Haroz, R. K., Ed.; Springer Netherlands: Dordrecht, 1983, 49-58.

(21) Müller, E.; Pfanz, H. Ber. Dtsch. Chem. Ges. B 1941, 74, 1051.

(22) (a) Kamada, K.; Ohta, K.; Kubo, T.; Shimizu, A.; Morita, Y.; Nakasuji, K.; Kishi, R.; Ohta, S.; Furukawa, S.-i.; Takahashi, H.; Nakano, M. Angew. Chem. Int. Ed. 2007, 46, 3544. (b) Sun, Z.; Ye, Q.; Chi, C.; Wu, J. Chem. Soc. Rev. 2012, 41, 7857. (c) Morita, Y.; Suzuki, S.; Sato, K.; Takui, T. Nat. Chem. 2011, 3, 197. (d) Nakano, M.; Champagne, B. J. Phys. Chem. Lett. 2015, 6, 3236.

(23) Tan, G.; Wang, X. Acc. Chem. Res. 2017, 50, 1997.

(24) (a) Li, G.; Phan, H.; Herng, T. S.; Gopalakrishna, T. Y.; Liu, C.; Zeng, W.; Ding, J.; Wu, J. Angew. Chem. Int. Ed. 2017, 56, 5012. (b) Liu, J.; Ma, J.; Zhang, K.; Ravat, P.; Machata, P.; Avdoshenko, S.; Hennersdorf, F.; Komber, H.; Pisula, W.; Weigand, J. J.; Popov, A. A.; Berger, R.; Müllen, K.; Feng, X. J. Am. Chem. Soc. 2017, 139, 7513.

(25) Wang, J.; Xu, X.; Phan, H.; Herng, T. S.; Gopalakrishna, T. Y.; Li, G.; Ding, J.; Wu, J. Angew. Chem. Int. Ed. 2017, 56, 14154.

(26) Kato, K.; Osuka, A. Angew. Chem. Int. Ed. 2019, 58, 8978.

(27) (a) Hopkinson, M. N.; Richter, C.; Schedler, M.; Glorius, F. Nature 2014, 510, 485. (b) Rottschäfer, D.; Blomeyer, S.; Neumann, B.; Stammler, H.-G.; Ghadwal, R. S. Chem. Eur. J. 2018, 24, 380.

(28) (a) Ghadwal, R. S.; Azhakar, R.; Roesky, H. W. Acc. Chem. Res. 2013, 46, 444. (b) Wang, Y.; Robinson, G. H. Inorg. Chem. 2014, 53, 11815. (c) Wang, Y.; Robinson, G. H. Dalton Trans. 2012, 337. (d) Yao, S.; Xiong, Y.; Driess, M. Acc. Chem. Res. 2017, 50, 2026.

(29) (a) Walton, J. C.; Brahmi, M. M.; Monot, J.; Fensterbank, L.; Malacria, M.; Curran, D. P.; Lacote, E. J. Am. Chem. Soc. 2011, 133, 10312. (b) Ueng, S. H.; Solovyev, A.; Yuan, X.; Geib, S. J.; Fensterbank, L.; Lacote, E.; Malacria, M.; Newcomb, M.; Walton, J. C.; Curran, D. P. J. Am. Chem. Soc. 2009, 131, 11256. (c) Walton, J. C.; McFadden, T. R.; Curran, D. P. J. Am. Chem. Soc. 2017, 139, 16514.

(30) (a) Melaimi, M.; Jazzar, R.; Soleilhavoup, M.; Bertrand, G. Angew. Chem. Int. Ed. 2017, 56, 10046. (b) Soleilhavoup, M.; Bertrand, G. Acc. Chem. Res. 2015, 48, 256. (c) Martin, C. D.; Soleilhavoup, M.; Bertrand, G. Chem. Sci. 2013, 4, 3020. (d) Mondal, K. C.; Roy, S.; Roesky, H. W. Chem. Soc. Rev. 2016, 45, 1080. (e) Hansmann, M. M.; Melaimi, M.; Munz, D.; Bertrand, G. J. Am. Chem. Soc. 2018, 140, 2546. (f) Hansmann, M. M.; Melaimi, M.; Bertrand, G. J. Am. Chem. Soc. 2018, 140, 2206.

(31) (a) Vummaleti, S. V. C.; Nelson, D. J.; Poater, A.; Gomez-Suarez, A.; Cordes, D. B.; Slawin, A. M. Z.; Nolan, S. P.; Cavallo, L. Chem. Sci. 2015, 6, 1895. (b) Mondal, K. C.; Roy, S.; Maity, B.; Koley, D.; Roesky, H. W. Inorg. Chem. 2016, 55, 163.

(32) Viehe, H. G.; Janousek, Z.; Merenyi, R.; Stella, L. Acc. Chem. Res. $1985,18,148$.

(33) (a) Li, Y.; Chan, Y.-C.; Leong, B.-X.; Li, Y.; Richards, E.; Purushothaman, I.; De, S.; Parameswaran, P.; So, C.-W. Angew. Chem. Int. Ed. 2017, 56, 7573. (b) Gu, L.; Zheng, Y.; Haldón, E.; Goddard, R.; Bill, E.; Thiel, W.; Alcarazo, M. Angew. Chem. Int. Ed. 2017, 56, 8790. (c) Kundu, S.; Sinhababu, S.; Luebben, A. V.; Mondal, T.; Koley, D.; Dittrich, B.; Roesky, H. W.J. Am. Chem. Soc. 2018, 140, 151. (d) Kundu, S.; Samuel, P. P.; Sinhababu, S.; Luebben, A. V.; Dittrich, B.; Andrada, D. M.; Frenking, G.; Stückl, A. C.; Schwederski, B.; Paretzki, A.; Kaim, W.; Roesky, H. W. 
J.Am. Chem. Soc. 2017, 139, 11028. (e) Braunschweig, H.; Krummenacher, I.; Légaré, M.-A.; Matler, A.; Radacki, K.; Ye, Q. J. Am. Chem. Soc. 2017, 139, 1802.

(34) (a) Mahoney, J. K.; Martin, D.; Moore, C. E.; Rheingold, A. L.; Bertrand, G. J. Am. Chem. Soc. 2013, 135, 18766. (b) Hansmann, M. M.; Melaimi, M.; Bertrand, G. J. Am. Chem. Soc. 2017, 139, 15620. (c) Styra, S.; Melaimi, M.; Moore, C. E.; Rheingold, A. L.; Augenstein, T.; Breher, F.; Bertrand, G. Chem. Eur. J. 2015, 21, 8441. (d) Mahoney, J. K.; Martin, D.; Thomas, F.; Moore, C. E.; Rheingold, A. L.; Bertrand, G. J. Am. Chem. Soc. 2015, 137, 7519.

(35) (a) Eymann, L. Y. M.; Tskhovrebov, A. G.; Sienkiewicz, A.; Bila, J. L.; Živković, I.; Rønnow, H. M.; Wodrich, M. D.; Vannay, L.; Corminboeuf, C.; Pattison, P.; Solari, E.; Scopelliti, R.; Severin, K. J. Am. Chem. Soc. 2016, 138, 15126. (b) Back, J.; Park, J.; Kim, Y.; Kang, H.; Kim, Y.; Park, M. J.; Kim, K.; Lee, E. J. Am. Chem. Soc. 2017, 139, 15300. (c) Wang, Y.; Hickox, H. P.; Xie, Y.; Wei, P.; Blair, S. A.; Johnson, M. K.; Schaefer, H. F.; Robinson, G. H. J. Am. Chem. Soc. 2017, 139, 6859. (d) Kim, Y.; Lee, E. Chem. Eur. J. 2018, 24, 19110.

(36) (a) Ghadwal, R. S.; Lamm, J.-H.; Rottschäfer, D.; Schürmann, C. J.; Demeshko, S. Dalton Trans. 2017, 7664. (b) Ho, N. K. T.; Neumann, B.; Stammler, H.-G.; Menezes da Silva, V. H.; Watanabe, D. G.; Braga, A. A. C.; Ghadwal, R. S. Dalton Trans. 2017, 12027. (c) Ho, N. K. T.; Reichmann, S. O.; Rottschäfer, D.; Herbst-Irmer, R.; Ghadwal, R. S. Catalysts 2017, 7, 262. (d) Rottschäfer, D.; Schürmann, C. J.; Lamm, J.-H.; Paesch, A. N.; Neumann, B.; Ghadwal, R. S. Organometallics 2016, 35, 3421. (e) Ghadwal, R. S.; Reichmann, S. O.; Herbst-Irmer, R. Chem. Eur. J. 2015, 21, 4247.

(37) (a) Rottschäfer, D.; Ebeler, F.; Strothmann, T.; Neumann, B.; Stammler, H.-G.; Mix, A.; Ghadwal, R. S. Chem. Eur. J. 2018, 24, 3716. (b) Rottschäfer, D.; Neumann, B.; Stammler, H.-G.; Ghadwal, R. S. Chem. Eur. J. 2017, 23, 9044. (c) Rottschäfer, D.; Neumann, B.; Stammler, H.-G.; Kishi, R.; Nakano, M.; Ghadwal, R. S. Chem. Eur. J. 2019, 25, 3244. (d) Sharma, M.; Blomeyer, S.; Neumann, B.; Stammler, H.-G.; Ghadwal, R. S. Chem. Eur. J. 2019, 25, 8249. (e) Rottschäfer, D.; Sharma, M. K.; Neumann, B.; Stammler, H.-G.; Andrada, D. M.; Ghadwal, R. S. Chem. Eur. J. 2019, 25, 8127.

(38) Ghadwal, R. S. Dalton Trans. 2016, 16081.

(39) Gorodetsky, B.; Ramnial, T.; Branda, N. R.; Clyburne, J. A. C. Chem. Commun. 2004, 1972.
(40) McKenzie, I.; Brodovitch, J.-C.; Percival, P. W.; Ramnial, T.; Clyburne, J. A. C. J. Am. Chem. Soc. 2003, 125, 11565.

(41) Ghadwal, R. S.; Rottschäfer, D.; Schürmann, C. J. Z. Anorg. Allg. Chem. 2016, 642, 1236.

(42) Aldeco-Perez, E.; Rosenthal, A. J.; Donnadieu, B.; Parameswaran, P.; Frenking, G.; Bertrand, G. Science 2009, 326, 556.

(43) Rottschäfer, D.; Neumann, B.; Stammler, H.-G.; van Gastel, M.; Andrada, D. M.; Ghadwal, R. S. Angew. Chem. Int. Ed. 2018, 57, 4765.

(44) Giffin, N. A.; Hendsbee, A. D.; Masuda, J. D. Acta Crystallogr., Sect. E: Struct. Rep. Online 2010, 66, 02194.

(45) Rottschäfer, D.; Ho, N. K. T.; Neumann, B.; Stammler, H.-G.; van Gastel, M.; Andrada, D. M.; Ghadwal, R. S. Angew. Chem. Int. Ed. 2018, 57, 5838.

(46) Rottschäfer, D.; Neumann, B.; Stammler, H.-G.; Andrada, D. M.; Ghadwal, R. S. Chem. Sci. 2018, 9, 4970.

(47) Rottschäfer, D.; Busch, J.; Neumann, B.; Stammler, H.-G.; van Gastel, M.; Kishi, R.; Nakano, M.; Ghadwal, R. S. Chem. Eur. J. 2018, 24, 16537.

(48) Barry, B. M.; Soper, R. G.; Hurmalainen, J.; Mansikkamaki, A.; Robertson, K. N.; McClennan, W. L.; Veinot, A. J.; Roemmele, T. L.; Werner-Zwanziger, U.; Boere, R. T.; Tuononen, H. M.; Clyburne, J. A. C.; Masuda, J. D. Angew. Chem. Int. Ed. 2018, 57, 749.

(49) (a) Antoni, P. W.; Bruckhoff, T.; Hansmann, M. M. J. Am. Chem. Soc. 2019, 141, 9701. (b) Antoni, P. W.; Hansmann, M. M. J. Am. Chem. Soc. 2018, 140, 14823.

(50) Ravat, P.; Baumgarten, M. Phys. Chem. Chem. Phys. 2015, 17, 983.

(51) Kamada, K.; Ohta, K.; Shimizu, A.; Kubo, T.; Kishi, R.; Takahashi, H.; Botek, E.; Champagne, B.; Nakano, M. J. Phys. Chem. Lett. 2010, 1, 937.

(52) (a) Ito, S.; Nagami, T.; Nakano, M. J. Photochem. Photobiol., C 2018, 34, 85. (b) Nakano, M. Chem. Rec. 2017, 17, 27. (c) Minami, T.; Ito, S.; Nakano, M. J. Phys. Chem. Lett. 2013, 4, 2133.

(53) (a) Messelberger, J.; Grünwald, A.; Pinter, P.; Hansmann, M. M.; Munz, D. Chem. Sci. 2018, 9, 6107. (b) Chen, M.; Bae, Y. J.; Mauck, C. M.; Mandal, A.; Young, R. M.; Wasielewski, M. R. J. Am. Chem. Soc. 2018, 140, 9184. (c) Casanova, D. Chem. Rev. 2018, 118,7164

(54) Fukuda, K.; Suzuki, Y.; Matsui, H.; Nagami, T.; Kitagawa, Y.; Champagne, B.; Kamada, K.; Yamamoto, Y.; Nakano, M. ChemPhysChem 2017, 18, 142. 